\title{
Utilization of palm oil mill effluent for polyhydroxyalkanoate production and nutrient removal using statistical design
}

\author{
M. F. Md. Din · M. Ponraj • M. Van Loosdrecht • \\ Z. Ujang $\cdot$ S. Chelliapan $\cdot$ V. Zambare
}

Received: 27 January 2012/Revised: 21 February 2013/Accepted: 4 March 2013/Published online: 4 April 2013

(C) Islamic Azad University (IAU) 2013

\begin{abstract}
The optimization for poly- $\beta$-hydroxyalkanoate production was carried out with nutrient removal efficiency for total organic carbon (TOC), phosphate, and nitrate from palm oil mill effluent waste. The experiment was conducted in a fabricated fed-batch reactor and the data obtained was analyzed using central composite rotatable design and factorial design for response surface methodology as a systematic approach for designing the experiment statistically to obtain valid results with minimum effort, time, and resources. The analysis of numerical optimization with propagation of error showed that $66 \%$ of poly- $\beta$-hydroxyalkanoate production can be obtained with nutrient removal of TOC and nitrate by 19 and $3 \%$, respectively. However, phosphate removal efficiency was not found to be much effective. More over, the chemical oxygen demand: nitrogen phosphate $(509 \mathrm{~g} / \mathrm{g} \mathrm{N})$, chemical oxygen demand: phosphate $(200 \mathrm{~g} / \mathrm{g} \mathrm{P})$, air flow rate $(0.59 \mathrm{~L} / \mathrm{min})$, substrate feeding rate $(20 \mathrm{~mL} / \mathrm{min})$, and cycle length $(20 \mathrm{~h})$ were the
\end{abstract}

M. F. Md. Din · M. Ponraj ( $)$ · S. Chelliapan

Faculty of Civil Engineering, Institute of Environmental and

Water Resource Management (IPASA), Water Research

Alliance, Universiti Teknologi Malaysia, 81310 Skudai,

Johor, Malaysia

e-mail: goldking1977@gmail.com

M. Van Loosdrecht

Kluyver Laboratory for Biotechnology, Department of Biochemical Engineering, Delft University of Technology, Julianalaan 67, 2628 BC Delft, The Netherlands

\section{Z. Ujang}

Faculty of Natural and Chemical Engineering, Universiti

Teknologi Malaysia, 81310 Skudai, Johor, Malaysia

\section{Zambare}

Sequence Biotech Pvt. Ltd., Wadivarhe, Tal-Igatpuri, Dist-Nashik 422403, India optimized variables for maximum poly- $\beta$-hydroxyalkanoate production and nutrient removal.

Keywords Biopolymer - Nitrate removal - Palm oil mill effluent $\cdot$ Phosphate removal $\cdot$ Statistical design

\section{Introduction}

First commercial production of poly- $\beta$-hydroxyalkanoates (PHAs) in the form of polyhydroxybutyrate (PHB) was reported in 1963 by Grace \& Co. in C \& EN Laurel, Md (Marchessaul 2009). PHAs can be classified by the number of carbon atoms in the monomer units. These are including the short-chain-length PHA ( $\left.\mathrm{PHA}_{\mathrm{SCL}}\right)$ of 3-5 carbon atoms, and the medium-chain-length PHA $\left(\mathrm{PHA}_{\mathrm{MCL}}\right)$ of

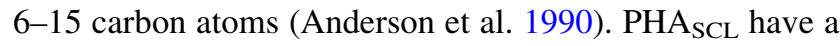
high degree of crystallinity, brittle and stiff, while $\mathrm{PHA}_{\mathrm{MCL}}$ are elastomeric with low crystallinity, low melting point and low tensile strength (Tokiwa and Calabia 2004). The strength and material properties of these polymers can be regulated by varying the copolymer composition (Otari and Ghosh 2009).

Biologically, PHA production was achieved using commercial substrates like acetate, glucose, glutamic acid (Wong et al. 2000; Reddy et al. 2003; Salehizadeh and Van Loosdrecht 2004). But still the production cost of PHA is very high and it has some operational problems in scaling up (Yu et al. 1998). Most of these polymers have been explored in organic wastes as a renewable source under the mixed culture development (Salehizadeh and Van Loosdrecht 2004). Since last decade, bio-industrial waste for PHA production have attracted much attention (Ahn et al. 2000; Fuchtenbusch et al. 2000; Hong et al. 2000; Wong et al. 2000; Hassan et al. 2002). Some of the renewable 
sources are palm oil mill effluent (POME), vegetable oils, molasses, brewery wastes, etc. Among all the bio-industrial waste, palm oil waste is highly generated in Malaysia, which is the cheapest and easily available carbon source for PHA production. Malaysia and Indonesia generate 13 million tons of palm oil waste annually (Lam and Lee 2011).

Palm oil mill effluent are huge quantities of waste generated from palm oil mill industry which is a hot, acidic ( $\mathrm{pH}$ between 4 and 5), brownish colloidal suspension containing high concentrations of organic matter, high amounts of total solids $\left(40,500 \mathrm{mg} \mathrm{L}^{-1}\right)$, oil and grease $\left(4,000 \mathrm{mg} \mathrm{L}^{-1}\right)$, COD $\left(50,000 \mathrm{mg} \mathrm{L}^{-1}\right)$, and BOD $\left(25,000 \mathrm{mg} \mathrm{L}^{-1}\right)$ (Salmiati et al. 2007). POME has been reported for its suitability for PHA production because it consists of high organic acids (Mumtaz et al. 2010). However, POME is usually present in a complex form, which cannot be directly utilized by PHA-producing bacterial species. Therefore, anaerobic treatment has been proposed by many researchers for effective hydrolysis and acidogenesis of wastes to short-chain volatile fatty acids (VFAs), which are fatty acids with a carbon chain of six carbons or fewer like acetic, butyric, and propionic acids and followed by PHA production. It is well known that a bacterial cell in a batch scale reactor is exposing to diverse operational conditions. Hence, much work has been done on studying the transient behavior of these bioprocesses (Serafim et al. 2004). However, very few research has been addressed on the optimization of the interacting effect of various operating conditions such as cultivation period, feeding rate, oxygen saturation, etc. (Md Din et al. 2005). Recently, statistical models provide a systematic and efficient plan for interactive experimentation to achieve certain goals in comparison to traditional method of optimization. Optimization using traditional "one factor-at-a-time" technique requires a considerable amount of work and time. However, statistical analysis methods like factorial experimental design and response surface methodology (RSM), involves minimum number of experiments for a large number of factors with interactive effect within the factors (Bocchini et al. 2002). Most frequently used statistical methods were evolutionary operation (Kumar et al. 2011), RSM (Sreekumar et al. 1999) and central composite rotatable design (CCRD) (Rodríguez-Carmona et al. 2011). Among these methods, RSM has been successfully applied for various fermentations and bioprocesses (Watier et al. 1996; Lee and Chen 1997; Dey et al. 2001). However, CCRD enables the significant factor(s) and interactive factors to be identified quantitatively and it is often recommended for sequential experimentation. Also, a CCRD is employed for fitting the second-order polynomial because it is an economical way to obtain the maximum amount of information with the fewest number of experiments on mixing time or a dependent variable. An empirical equation in the form of a second-order polynomial was obtained with specified and limited data (Vijayendra et al. 2007).

Many reports were available on the PHA production rate and productivity, however, less attention has been made on PHA production and simultaneously nutrient removal using statistical analysis. In the present study, we report the statistical method for PHA production and nutrient removal [total organic carbon (TOC), phosphate, and nitrate]. This study was conducted during January-June, 2006 at Laboratory of Environmental Engineering, Faculty of Civil Engineering, Universiti Teknologi Malaysia, Skudai, Johore, Malaysia.

\section{Materials and methods}

Substrates and inoculum development

Raw POME was obtained from Bukit Besar Palm Oil Mill, Kulai, Johore, Malaysia and sewage sludge was obtained from a nearby facultative pond (anaerobic pond from POME), which is a natural method for wastewater treatment, consists of shallow man-made basins comprising a single or several series of anaerobic, facultative or maturation ponds. The primary treatment takes place in the anaerobic pond, which is mainly designed for removing suspended solids, and some of the soluble element of organic matter (BOD). The sewage sludge of facultative pond and raw POME (2:1) was mixed in the distilled water and treated as inoculum for fed batch process. The activated sludge was cultured in a stirred batch reactor (SBR) with working volume of $6 \mathrm{~L}$ (with $50 \%$ discharge level). SBRs are a variation of the activated-sludge process. They differ from activated-sludge plants because they combine all of the treatment steps and processes into a single basin, or tank, whereas conventional facilities rely on multiple basins. The operations of SBR were based on a fill-anddraw principle, which consists of five steps-fill, react, settle, decant, and idle. These steps could be altered for different operational applications.

\section{Fed-batch process}

The compositional analysis of the POME was done. Then both raw POME and sewage sludge were introduced as inoculums to acclimatize the autotrophic/heterotrophic 
bacteria in the sequencing batch reactor (SBR), which differs from activated-sludge plants because they combine all of the treatment steps and processes into a single basin, or tank, whereas conventional facilities rely on multiple basins. The SBR was operated with working volume of $6 \mathrm{~L}$ (with $50 \%$ discharge level) and two propellers. The microbial population in the inoculums was developed for $24 \mathrm{~h}$ of incubation under the non-limiting nutrient concentrations. Then, the acclimatization of biomass concentration has been performed for 3-4 weeks. The media used for nutrient adaptation for microorganism under fed-batch control system contained $(\mathrm{g} / \mathrm{L}), 1.50, \mathrm{FeCl}_{3} \cdot 6 \mathrm{H}_{2} \mathrm{O} ; 0.15$, $\mathrm{H}_{3} \mathrm{BO}_{3} ; 0.03, \mathrm{CuSO}_{4} \cdot 5 \mathrm{H}_{2} \mathrm{O} ; 0.12, \mathrm{MnCl}_{2} \cdot 4 \mathrm{H}_{2} \mathrm{O} ; 0.06$, $\mathrm{Na}_{2} \mathrm{MoO}_{4} \cdot 2 \mathrm{H}_{2} \mathrm{O} ; 0.12, \mathrm{ZnSO}_{4} \cdot 7 \mathrm{H}_{2} \mathrm{O} ; 0.15, \mathrm{COCl}_{2} \cdot 6 \mathrm{H}_{2} \mathrm{O}$; 10.0, ethylenediamintetraacetic acid (EDTA); $0.18, \mathrm{KI}$;
15.5, $\mathrm{NH}_{4} \mathrm{Cl} ; 7.59, \mathrm{KH}_{2} \mathrm{PO}_{4} ; 0.2, \mathrm{MgSO}_{4} \cdot 7 \mathrm{H}_{2} \mathrm{O}$. The fedbatch cultivation was optimized at three stages. First, a high proliferation in growth phase; second, steady-state phase and third, was an integrated process optimization for PHA production and nutrient removal. These three stages were apparently interconnected and an overall fed-batch optimization scheme was proposed as (a) preliminary study on bioprocess and biotechnology engineering, and understanding the specific activity, (b) design parameters, calibration or verification, and (c) process design and set-up the fed-batch configuration. The operating principles of a batch activated sludge system are characterized in just three discrete periods as fill (mineral feeding, 5 min and carbon feeding, $60 \mathrm{~min}$ operation), reaction (aerobic for $>50 \%$ solids), drawing (desludging, 10 min operation). In

Table 1 Experimental runs conducted in dynamic aerobic study with actual and coded levels

\begin{tabular}{|c|c|c|c|c|c|c|c|c|}
\hline \multirow[t]{2}{*}{ Run code } & \multicolumn{2}{|c|}{ COD:N:P (gCOD/g N/g P) } & \multicolumn{2}{|c|}{ AFD (L/min) } & \multicolumn{2}{|l|}{ CL (h) } & \multicolumn{2}{|c|}{ SFR (ml/min) } \\
\hline & Actual & Coded & Actual & Coded & Actual & Coded & Actual & Coded \\
\hline 1 & 550 & {$[+1]^{\mathrm{b}}$} & 0.875 & {$[-1]$} & 15.5 & {$[-1]$} & 27.5 & {$[-1]$} \\
\hline 2 & 450 & {$[-1]$} & 1.625 & {$[+1]$} & 15.5 & {$[-1]$} & 27.5 & {$[-1]$} \\
\hline 3 & 450 & {$[-1]$} & 0.875 & {$[-1]$} & 22.5 & {$[+1]$} & 27.5 & {$[-1]$} \\
\hline 4 & 550 & {$[+1]$} & 1.625 & {$[+1]$} & 22.5 & {$[+1]$} & 27.5 & {$[-1]$} \\
\hline 5 & 450 & {$[-1]$} & 0.875 & {$[-1]$} & 15.5 & {$[-1]$} & 42.5 & {$[+1]$} \\
\hline 6 & 550 & {$[+1]$} & 1.625 & {$[+1]$} & 15.5 & {$[-1]$} & 42.5 & {$[+1]$} \\
\hline 7 & 550 & {$[+1]$} & 0.875 & {$[-1]$} & 22.5 & {$[+1]$} & 42.5 & {$[+1]$} \\
\hline 8 & 450 & {$[-1]$} & 1.625 & {$[+1]$} & 22.5 & {$[+1]$} & 42.5 & {$[+1]$} \\
\hline 9 & 500 & [0] & 1.250 & {$[0]$} & 19.0 & [0] & 35.0 & [0] \\
\hline 10 & 500 & {$[0]$} & 1.250 & {$[0]$} & 19.0 & {$[0]$} & 35.0 & {$[0]$} \\
\hline 11 & 450 & {$[-1]$} & 0.875 & {$[-1]$} & 15.5 & {$[-1]$} & 27.5 & {$[-1]$} \\
\hline 12 & 550 & {$[+1]$} & 1.625 & {$[+1]$} & 15.5 & {$[-1]$} & 27.5 & {$[-1]$} \\
\hline 13 & 550 & {$[+1]$} & 0.875 & {$[-1]$} & 22.5 & {$[+1]$} & 27.5 & {$[-1]$} \\
\hline 14 & 450 & {$[-1]$} & 1.625 & {$[+1]$} & 22.5 & {$[+1]$} & 27.5 & {$[-1]$} \\
\hline 15 & 550 & {$[+1]$} & 0.875 & {$[-1]$} & 15.5 & {$[-1]$} & 42.5 & {$[+1]$} \\
\hline 16 & 450 & {$[-1]$} & 1.625 & {$[+1]$} & 15.5 & {$[-1]$} & 42.5 & {$[+1]$} \\
\hline 17 & 450 & {$[-1]$} & 0.875 & {$[-1]$} & 22.5 & {$[+1]$} & 42.5 & {$[+1]$} \\
\hline 18 & 550 & {$[+1]$} & 1.625 & {$[+1]$} & 22.5 & {$[+1]$} & 42.5 & {$[+1]$} \\
\hline 19 & 500 & {$[0]$} & 1.250 & {$[0]$} & 19.0 & {$[0]$} & 35.0 & {$[0]$} \\
\hline 20 & 500 & {$[0]$} & 1.250 & {$[0]$} & 19.0 & {$[0]$} & 35.0 & [0] \\
\hline 21 & 400 & {$[-2]$} & 1.250 & {$[0]$} & 19.0 & {$[0]$} & 35.0 & {$[0]$} \\
\hline 22 & 600 & {$[+2]$} & 1.250 & {$[0]$} & 19.0 & [0] & 35.0 & {$[0]$} \\
\hline 23 & 500 & {$[0]$} & 0.500 & {$[-2]$} & 19.0 & {$[0]$} & 35.0 & [0] \\
\hline 24 & 500 & {$[0]$} & 2.000 & {$[+2]$} & 19.0 & {$[0]$} & 35.0 & [0] \\
\hline 25 & 500 & {$[0]$} & 1.250 & {$[0]$} & 12.0 & {$[-2]$} & 35.0 & [0] \\
\hline 26 & 500 & {$[0]$} & 1.250 & {$[0]$} & 26.0 & {$[+2]$} & 35.0 & [0] \\
\hline 27 & 500 & [0] & 1.250 & {$[0]$} & 19.0 & {$[0]$} & 20.0 & {$[-2]$} \\
\hline 28 & 500 & {$[0]$} & 1.250 & {$[0]$} & 19.0 & {$[0]$} & 50.0 & {$[+2]$} \\
\hline 29 & 500 & {$[0]$} & 1.250 & {$[0]$} & 19.0 & {$[0]$} & 35.0 & {$[0]$} \\
\hline 30 & 500 & [0] & 1.250 & {$[0]$} & 19.0 & {$[0]$} & 35.0 & {$[0]$} \\
\hline
\end{tabular}

COD:N:P chemical oxygen demand:nitrate:phosphate, $A F D$ air flow rate, $C L$ cycle length, $S F R$ substrate feeding rate 
order to control the fast uptake and storage polymer, the system was operated in continuous reaction period, which means no settling or allowing the idle phase [hydraulic retention time $($ HRT $)=$ sludge retention time $($ SRT)], which denotes HRT for the period that a liquid remain inside a bioreactor and for SRT it refers to the period that a sludge/biomass remains inside a bioreactor. The length of each phase was varied independently on the cultivated tank. The influent was pumped into the tank and mixed with the biomass that settled during the previous cycle until the time for filling reached. During pulse fill, a high substrate concentration is almost instantaneously available for the microorganisms. At steady-state condition, microorganisms will generate two major phases, which are feast or growth phase (with nutrient supply) and famine or accumulation phase (without nutrient supply) condition. In order to control the feast and famine period, most of the operations were influenced by nitrification. To prevent the possible influence of nitrification on the measurements, at least $100 \mathrm{mg}$ of allylthiourea was added to the reactor before each sampling cycle. Reactors and tubes were periodically cleaned to avoid the proliferation of bacteria on lines and walls. The length of the feast period in the pulse-fed system was evaluated from dissolved oxygen (DO) measurements continuously recorded by the data acquisition.

\section{Analytical procedures}

Samples were taken from the reactor and centrifuged using Sorval RC-5B centrifuge (Hermmicks, Germany) at $10,000 \mathrm{rpm}$ for $10 \mathrm{~min}$. The supernatant was then filtered by using PVDF-syringe filter and were analyzed for ammoniacal nitrogen $\left(\mathrm{NH}_{4}-\mathrm{N}\right)$, phosphate $\left(\mathrm{PO}_{4}-\mathrm{P}\right)$, TOC and VFA in accordance with standard methods (Clesceri et al. 1995). The carbon concentration in the supernatant was measured by gas chromatography (GC, Shimadzu, Japan), while $\mathrm{NH}_{4}-\mathrm{N}, \mathrm{NO}_{3}-\mathrm{N}$ and $\mathrm{PO}_{4}-\mathrm{P}$ concentrations in the supernatant were measured spectrophotometrically (HACH Spectrophotometer DR-4000U, USA) at 630, 450, and $520 \mathrm{~nm}$, respectively. The supernatant of VFAs (acetic acid, propionic acid, and butyric acid) were measured by GC14A with flame ionization detector.

\section{PHA quantification}

Samples for PHA quantification were added to $10 \mathrm{~mL}$ tubes containing two drops of formaldehyde in order to stop all biological activity immediately. The PHB content was washed with $5 \mathrm{mM} \mathrm{KH} \mathrm{KO}_{4}$ buffer ( $\left.\mathrm{pH} 7\right)$ and centrifuged at $10,000 \mathrm{rpm}$ for $10 \mathrm{~min}$. The supernatant was freeze-dried using freezer-dryer for $24 \mathrm{~h}$. Dried solids were weighed and stored in screw-cap bottle. Dried biomass was saponified and the PHA was quantified using GC method. In qualitative measurement, the dried biomass for PHA constituent was determined by extraction, hydrolyzation, and esterification in a mixture of hydrochloric acid, 1-propanol, and dichloroethane at $100{ }^{\circ} \mathrm{C}$ followed by addition of $2 \mathrm{~mL}$ of chloroform. The screw-cap bottle was then digested at $100{ }^{\circ} \mathrm{C}$ for $2 \mathrm{~h}$ using digester reflux (HACH digester, USA) and allowed to cool followed by addition of $3 \mathrm{~mL}$ of distilled water in each bottle. Bottles were shaken for $10 \mathrm{~min}$ and allowed to separate the organic and inorganic layer. After complete digestion, $1 \mu \mathrm{L}$ of the chloroform phase (bottom layer) was injected into the GC and the PHA concentration (\%) was calculated. Benzoic acid $(2 \mathrm{~mL})$ was used as an internal standard throughout the procedure.

\section{Experimental design}

The experimental design was evaluated using single observation obtained from the optimum fraction of PHA productivity. The RSM analysis was only performed in four main variables [COD:N:P (400-600 g COD/g N/g P), air flow rate (AFR) $(0.5-2 \mathrm{~L} / \mathrm{min})$, cycle length (CL) (12-26 h), and substrate feeding rate (SFR) $(20-50 \mathrm{~mL} / \mathrm{min})]$ with POME as a substrate. The experimental design was carried out at four factor at five levels $(-2,-1,0,+1,+2)$ using MINITAB $^{\mathrm{TM}}$ (version 13.2, UK). A total of 30 runs were used to optimize the production process divided into three parts: a $2^{4}$ Hadamard matrix factorial run (1-8 and 11-18), star point runs (21-28) and center point runs (9-10, 19-20, and 29-30) (Table 1). The interactive and synergistic effect of the factors were determined based on the Hadamard matrix and center point runs, while the non-linear response behavior was analyzed using star point and center point runs. The center point runs were also repeated six times in order to allow better estimation of the experimental error. All of the experiments were conducted in $8 \mathrm{~h}$ length, except for CL study.

Model validation

An independent experiment was used to verify the optimum conditions identified in the two-level factorial experiment. The verification consisted of triplicate runs comparing the control bioprocess (i.e., original non-optimal medium) and the optimized growth medium with $80 \%$ air in the gas phase (at least $10 \mathrm{~L} / \mathrm{min}$ ). After 7 days, the samples were removed and analyzed for PHA production. 

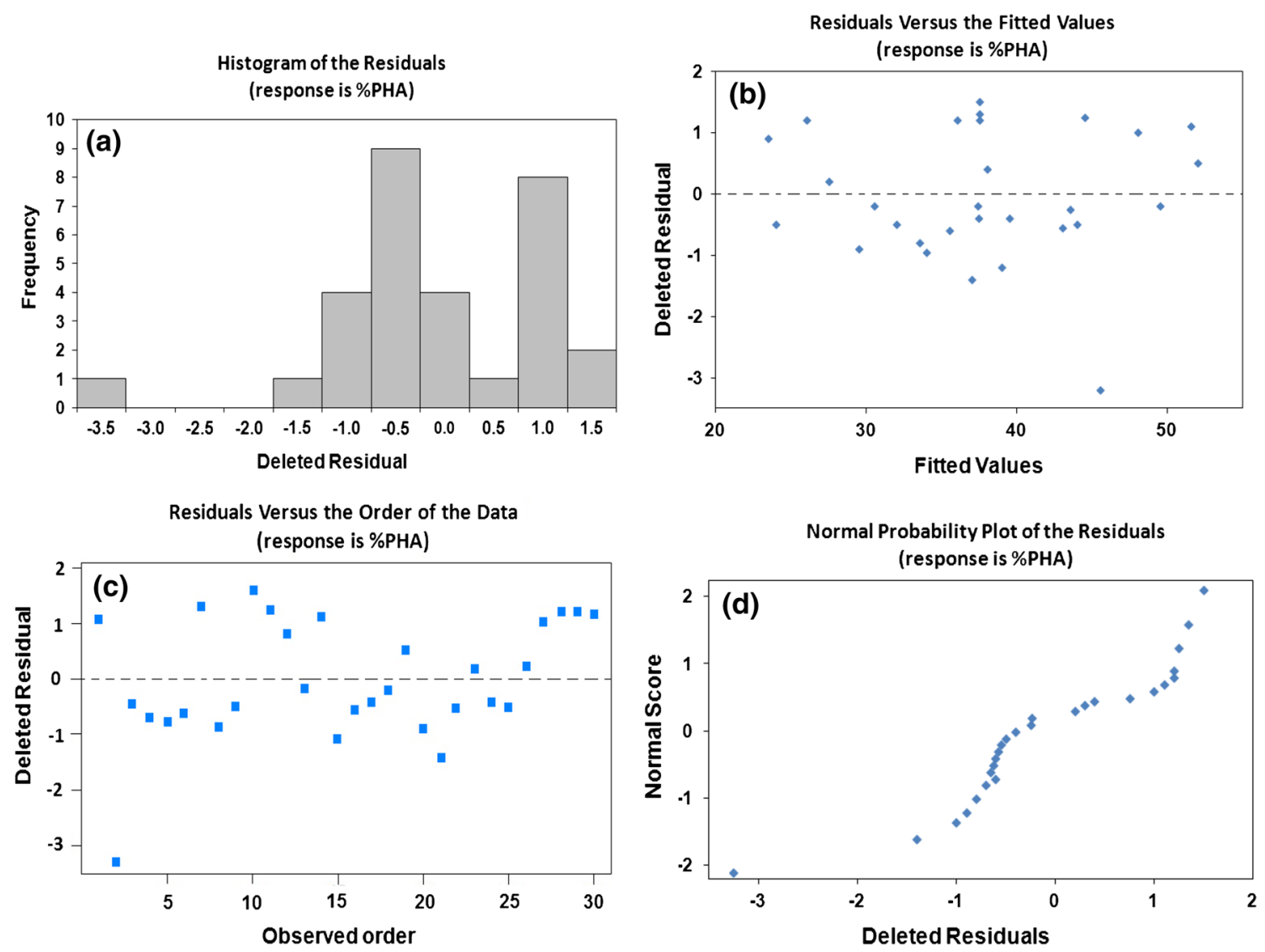

Fig. 1 Residual diagnostics of response model for \%PHA. a Histogram, b deleted residuals versus fitted values, c deleted residuals versus observation order, $\mathbf{d}$ normal probability

\section{Results and discussion}

The compositional analysis of POME showed high COD $(87.30 \pm 0.54 \mathrm{~g} / \mathrm{L})$, soluble COD $(41.52 \pm 0.61 \mathrm{~g} / \mathrm{L})$, total solids $(31.05 \pm 0.49 \mathrm{~g} / \mathrm{L})$, total volatile solids $(27.60 \pm 0.94 \mathrm{~g} / \mathrm{L})$, lactic acid $(3.90 \pm 1.22 \mathrm{~g} / \mathrm{L})$, and acetic acid $(3.62 \pm 0.31 \mathrm{~g} / \mathrm{L})$. Also the pit sludge POME contained phosphates and nitrogen which are very good for PHA production. POME was found to be with numerous fatty acid components, thus the PHA production will not limit for 3-hydroxybutyrate (3HB) monomer (Malaysia Palm Oil Board 2005).

\section{Model diagnostic and RSM}

A common and powerful approach for optimizing a multivariate system is the RSM (Myers and Montgomery 2002). A large absolute studentized residual (deleted residuals) indicated the observation in the model that increases the error variance or it had a large affect upon the parameter estimates, or both. The major diagnostic method is residual (observed minus predicted) analysis as shown in Fig. 1, providing diagnostic for residual behavior. There were several residuals graphs to test the model assumptions. The predictive model used to generate response surface graphs and contour plots contains equation for describing linear and quadratic effects of the process and interaction between process factors and the response (\%PHA, \% TOC, $\% \mathrm{PO}_{4}$, and $\% \mathrm{NO}_{3}$ ). MINITAB ${ }^{\mathrm{TM}}$ divided the data into intervals represented as bars in a high-resolution histogram, as asterisks in a character histogram. As depicted in the Fig. 1a-d, the response model for PHAs production was fixed to the normal distribution. The next analysis was to study the deleted residuals versus the fitted value (Fig. 1b). The result showed that there was no systematic pattern in the plot. All points were decreased within a horizontal band centered at zero. Departure from suggests a violation of the constant variance assumption. The size of deleted residuals was found to be independent of its fitted value and that spread was about the same across all levels of the fitted values. Deleted residuals versus observation order (number) graphs revealed any time-based affects or sequential component (Fig. 1c). The positive effect of PHA production in four variables was quantified through Fig. 1b-d. A pictorial representation of the effect is shown in Fig. 1a, where the highest frequency obtained 
Table 2 ANOVA and regression analysis for selected responses

\begin{tabular}{|c|c|c|c|c|c|c|}
\hline \multirow[t]{2}{*}{ Response } & \multirow[t]{2}{*}{ Predictor/analysis } & \multirow[t]{2}{*}{ Constant } & \multicolumn{4}{|l|}{ Factor } \\
\hline & & & $A$ & $B$ & $C$ & $D$ \\
\hline \multirow[t]{7}{*}{ PHA production } & Coefficient & 24.66 & 0.078 & -6.294 & 0.071 & 0.236 \\
\hline & SE Coeff. & 17.90 & 0.026 & 3.899 & 0.557 & 0.097 \\
\hline & $T$ & 1.38 & 3.00 & -1.61 & 0.13 & -2.42 \\
\hline & $P$ & 0.18 & 0.006 & 0.119 & 0.900 & 0.023 \\
\hline & VIF & 1.00 & 1.00 & 1.00 & 1.00 & 1.00 \\
\hline & \multicolumn{6}{|c|}{ DW statistic $=1.55$} \\
\hline & \multicolumn{6}{|c|}{$P=0.008, R^{2}=41.2 \%, R^{2}(\mathrm{adj})=31.8 \%$} \\
\hline \multirow[t]{7}{*}{ TOC removal } & Coefficient & -1.74 & 0.03 & -0.34 & -0.03 & -0.03 \\
\hline & SE Coeff. & 8.121 & 0.012 & 1.769 & 0.253 & 0.044 \\
\hline & $T$ & -0.21 & 2.42 & -0.19 & -0.10 & -0.62 \\
\hline & $P$ & 0.832 & 0.023 & 0.849 & 0.923 & 0.538 \\
\hline & VIF & 1.00 & 1.00 & 1.00 & 1.00 & 1.00 \\
\hline & \multicolumn{6}{|c|}{ DW statistic $=1.72$} \\
\hline & \multicolumn{6}{|c|}{$p=0.213, R^{2}=20.1 \%, R^{2}(\operatorname{adj})=7.3 \%$} \\
\hline \multirow[t]{7}{*}{$\mathrm{NO}_{3}-\mathrm{N}$ removal } & Coefficient & 10.00 & 0.007 & -4.068 & -0.148 & -0.038 \\
\hline & SE Coeff. & 8.139 & 0.012 & 1.773 & 0.253 & 0.044 \\
\hline & $T$ & 1.23 & 0.62 & -2.29 & -0.58 & -0.87 \\
\hline & $P$ & 0.231 & 0.543 & 0.030 & 0.566 & 0.395 \\
\hline & VIF & - & 1.00 & 1.00 & 1.00 & 1.00 \\
\hline & \multicolumn{6}{|l|}{ DW statistic $=1.75$} \\
\hline & \multicolumn{6}{|c|}{$p=0.186, R^{2}=21.2 \%, R^{2}(\operatorname{adj})=8.6 \%$} \\
\hline \multirow[t]{7}{*}{$\mathrm{PO}_{4}-\mathrm{P}$ removal } & Coefficient & 0.244 & -0.027 & 1.549 & 0.302 & 0.087 \\
\hline & SE Coeff. & 7.987 & 0.012 & 1.740 & 0.249 & 0.044 \\
\hline & $T$ & 0.03 & -2.30 & 0.89 & 1.21 & 1.99 \\
\hline & $P$ & 0.976 & 0.030 & 0.382 & 0.236 & 0.057 \\
\hline & VIF & - & 1.00 & 1.00 & 1.00 & 1.00 \\
\hline & \multicolumn{6}{|c|}{ DW statistic $=2.14$} \\
\hline & \multicolumn{6}{|c|}{$p=0.043, R^{2}=31.5 \%, R^{2}(\operatorname{adj})=20.6 \%$} \\
\hline
\end{tabular}

VIF variance inflation factor, $D W$ Durbin-Watson, $A$ COD:N:P (chemical oxygen demand: nitrate: phosphate), $B$ air flow rate, $C$ cycle length, $D$ substrate feeding rate

at -0.5 of deleted residual, which means in the normal range ( -2 to 2$)$.

The variance inflation factor (VIF) is used to detect whether one predictor has a strong linear association with the remaining predictors (the presence of multicollinearity among the predictors). VIF measures how much the variance of an estimated regression coefficient increases if the predictors are correlated (multicollinear). The VIF of 1 indicates the predictor with no relation (Montgomery and Peck 1982). The largest VIF among all predictors is often used as an indicator of severe multicollinearity. Montgomery and Peck (1982) suggest that when VIF is $>5-10$, then the regression coefficients were poorly estimated. Since the results from Table 2 did not show any relation between predictors, therefore, multiple regressions have been computed, afterward. However, the computed VIF value significantly indicated the non-severely multi-collinear analysis. The Durbin-Watson (DW) statistic tested the residuals to determine if there was any significant correlation based on the order in which they occurred in the data file. Due to the fact that the DW value exceeded 1.4 and there were probably no significant autocorrelation in the residuals. The coefficient of determination $\left(R^{2}\right)$ indicated that the model could only reach as high as $41.3 \%$ of the variability in PHA production. Then, the adjusted $R^{2}$ statistic, which is more suitable for comparing models with different numbers of independent variables, was only $31.8 \%$. Therefore, the model showed that the interaction effect of TOC, AFR, CL, and SFR was unable to predict. As a conclusion, the study suggested the residual diagnostic to evaluate the predictor of PHA production, TOC removal, $\mathrm{NO}_{3}-\mathrm{N}$ removal, and $\mathrm{PO}_{4}-\mathrm{P}$ removal. 

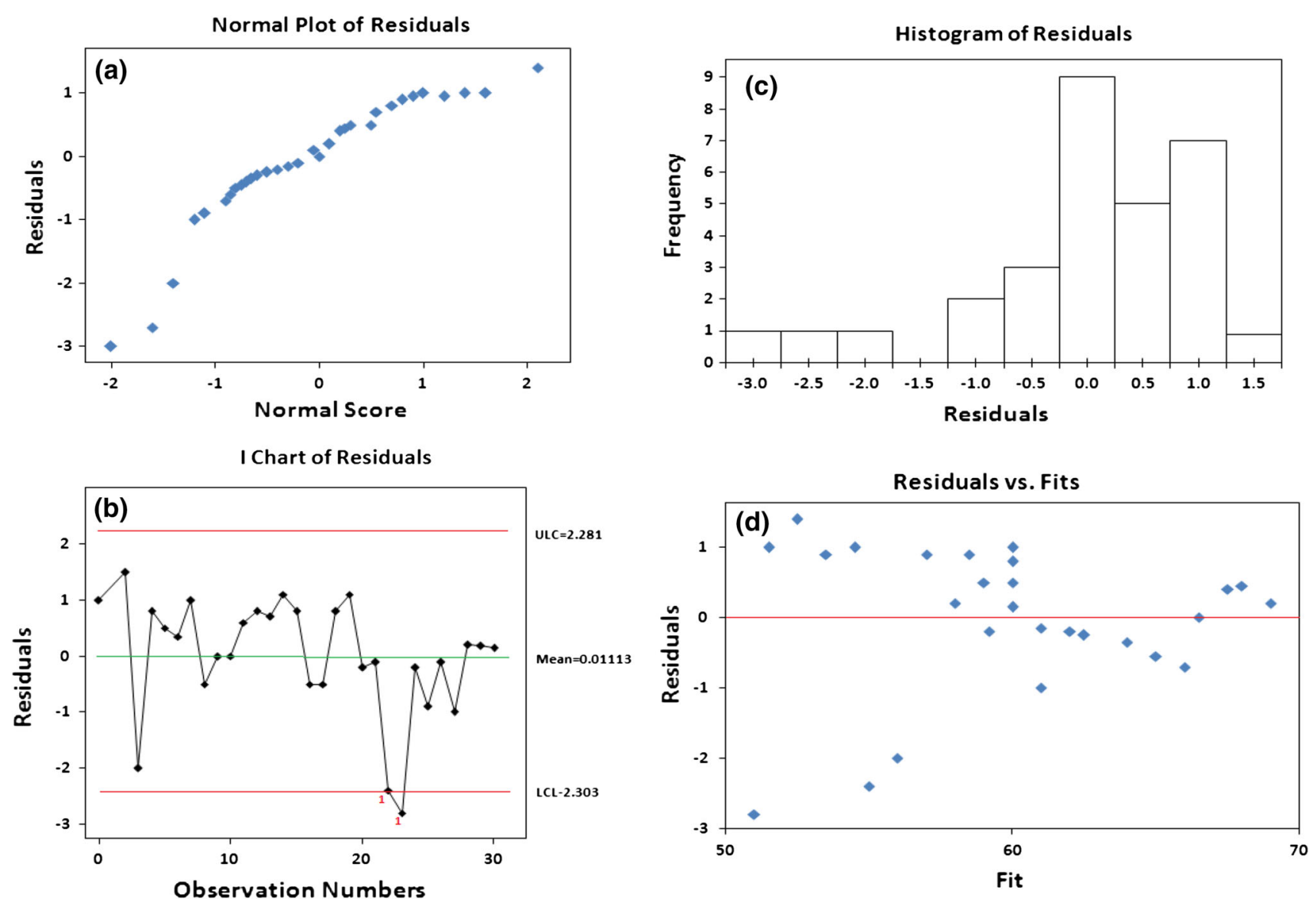

Fig. 2 Residual model diagnostic for \%PHA in four variables (COD:N:P, AFR, CL, and SFR). a Normal plot, b I-Chart, $\mathbf{c}$ histogram, d residuals versus fits

The residuals from the best two-predictor model of the best subsets regression has been chosen to obtain the satisfactory result from regression model. In this multiple regression, the third variable from the best three-predictor model may not add appreciably to the fit. The residual patterns examined from the best two-predictor model to further examine the goodness-of-fit. Figure 2 showed the residuals plots procedure, which can generate four plots in best two-predictor model (e.g., PHA production). In general, the normal plot (Fig. 2a) shows an approximately linear pattern that is relatively consistent with a normal distribution (-2 to 2). Similarly, the histogram exhibits a pattern that is consistent with a sample from a normal distribution (Fig. 2c). However, the chart of residuals depicted in Fig. 2b illustrated a control chart of individual observations. It reveals that one point labeled with number 1 (at 22 and 23 observation number) is outside the three sigma limits [upper control limit, mean and lower control limit]. This flagged point indicated that the values are not significantly used for further analysis. Residual versus fit graph (Fig. 2d) display the real response data plotted against the fitted responses. Points above 2 or below -2 the mean areas of over or under fitted. Except the outlier, no significant violations were found in the model assumptions and the residual analysis. This design point seems to be due to measurement error rather than random experimental error. The plot of residuals versus fits shows that the fit tends to be better for intermediate predicted values (55-65). The scattered point showed the trend of fit for optimization of all factor of four variables.

The results suggested that only carbon ratio and AFR have significant effects to the particular responses (e.g. $\%$ PHA, \% TOC removal, etc.). From the analysis of the data in Table 5 by the least squares method, the following second-order model was fitted. Since the regression analysis did not show a correct evaluation (especially $\% \mathrm{PO}_{4}$ and $\% \mathrm{NO}_{3}$ ), the RSM was conducted and the regression equation for \% $\mathrm{PHA}, \% \mathrm{TOC}$ removal, $\% \mathrm{PO}_{4}$ removal, and $\% \mathrm{NO}_{3}$ removal are shown in Eqs. 1-4, respectively. 
Table 3 Results of the regression analysis of the CCRD

\begin{tabular}{|c|c|c|c|c|c|c|c|c|}
\hline \multirow[t]{2}{*}{ Term } & \multicolumn{2}{|c|}{$\%$ PHA production } & \multicolumn{2}{|c|}{$\%$ TOC removal } & \multicolumn{2}{|c|}{$\% \mathrm{PO}_{4}$ removal } & \multicolumn{2}{|c|}{$\% \mathrm{NO}_{3}$ removal } \\
\hline & Coefficient & $p$ value & Coefficient & $p$ value & Coefficient & $p$ value & Coefficient & $p$ value \\
\hline Constant & -861.896 & 0.000 & -356.315 & 0.000 & 561.714 & 0.000 & -574.108 & 0.002 \\
\hline$A$ & 1.308 & 0.063 & 0.218 & 0.096 & -0.809 & 0.358 & 0.627 & 0.005 \\
\hline$B$ & 173.412 & 0.002 & 56.182 & 0.016 & -94.604 & 0.002 & -12.176 & 0.518 \\
\hline$C$ & 37.673 & 0.773 & 17.121 & 0.731 & -10.836 & 0.574 & 40.097 & 0.275 \\
\hline$D$ & 12.340 & 0.424 & 10.498 & 0.282 & -17.824 & 0.169 & 5.165 & 0.761 \\
\hline$A^{2}$ & -0.001 & 0.099 & -0.0002 & 0.429 & 0.0003 & 0.228 & -0.0004 & 0.138 \\
\hline$B^{2}$ & -12.656 & 0.140 & -1.370 & 0.749 & 5.711 & 0.266 & -5.841 & 0.219 \\
\hline$C^{2}$ & -0.482 & 0.679 & -0.218 & 0.717 & -0.259 & 0.714 & -0.969 & 0.151 \\
\hline$D^{2}$ & 0.029 & 0.877 & -0.061 & 0.529 & 0.039 & 0.734 & -0.063 & 0.547 \\
\hline $\mathrm{AB}$ & -0.106 & 0.205 & -0.006 & 0.893 & 0.002 & 0.971 & -0.029 & 0.530 \\
\hline $\mathrm{AC}$ & -0.007 & 0.816 & 0.003 & 0.867 & 0.009 & 0.645 & -0.008 & 0.624 \\
\hline $\mathrm{AD}$ & -0.008 & 0.520 & -0.002 & 0.781 & 0.012 & 0.133 & 0.0001 & 0.977 \\
\hline $\mathrm{BC}$ & -3.968 & 0.335 & -1.850 & 0.384 & 3.090 & 0.222 & 1.515 & 0.508 \\
\hline BD & -1.191 & 0.466 & -0.847 & 0.321 & 1.256 & 0.215 & 0.506 & 0.579 \\
\hline CD & -0.487 & 0.428 & -0.323 & 0.313 & 0.499 & 0.191 & -0.148 & 0.665 \\
\hline Lack-of-fit & $p=0.008$ & & $p=0.138$ & & $p=0.000$ & & $p=0.000$ & \\
\hline
\end{tabular}

0.01-0.04, highly significant; $0.05-0.1$, significant; $0.1-0.2$, less significant; $>0.2$, insignificant; $A$ COD: N: P (chemical oxygen demand: nitrate: phosphate), $B$ air flow rate, $C$ cycle length, $D$ substrate feeding rate

$$
\begin{aligned}
& \% \mathrm{PHA}=67.2+0.0489 A-12.2 B \\
& \% \mathrm{TOC}_{\text {removal }}=16.4+0.0224 A-4.54 B \\
& \% \mathrm{PO}_{4 \text { removal }}=-29.1+7.59 B \\
& \% \mathrm{NO}_{3 \text { removal }}=-6.5+0.0447 A
\end{aligned}
$$

where $A$ is the variable for COD:N:P and $B$ is the variable for AFR.

Response surface analysis was carried out in this study to determine the second-order behavior of the factors, to model the relationship between the factors and the response and to find the factor settings that produce the best response. The predictive model used to generate response surface graphs and contour plots contains equations for linear, interaction, and quadratic processes of factors. When the problem involves the data that are subject to experimental errors, statistical methods measure the effects of change in operating variables and their mutual interactions on the process performance through factorial experimental designs.

In this study, the response surface was employed to determine the effect of the operational variables that was conducted in fed-batch study. If the environmental variables have no significant effect on the objective function, such as PHA production, the response surface will have a flat zone with respect to the variables. A wide range of the flat zone implies that the environmental variable can be controlled within the desired range in the scale-up bioreactor. On the other hand, if the operational variables have no significant interaction in regression analysis $(p>0.1)$, this means that the state variables in the scale-up bioreactor cannot be manipulated within the required range. It was then necessary to proceed to the second step, which is called as factorial design.

Table 3 illustrated the final constant values for model analysis. Except for the linear term, either $A$ (variable for COD:N:P) or $B$ (variable for AFR) $(p<0.05)$, none of the other (linear, quadratic, and interaction terms) were statistically significant. The final second-order polynomial equation for PHAs production, organic and nutrient removals after omitting $p$ value, is shown in Eqs. 5-8.

$\%$ PHA $=-861.896+1.308 A+173.412 B-0.001 A^{2}$

$\%$ TOC $=-356.313+218 A+56.182 B$

$\% \mathrm{PO}_{4}=561.714-94.604 B$

$\% \mathrm{NO}_{3}=-574.108+0.627 \mathrm{~A}$

The statistical significance of the model equation was evaluated by the $F$ test for analysis of variance (ANOVA), which showed that the regression is statistically significant at $95 \%(p<0.05)$ confidence level. The model $F$ value of 

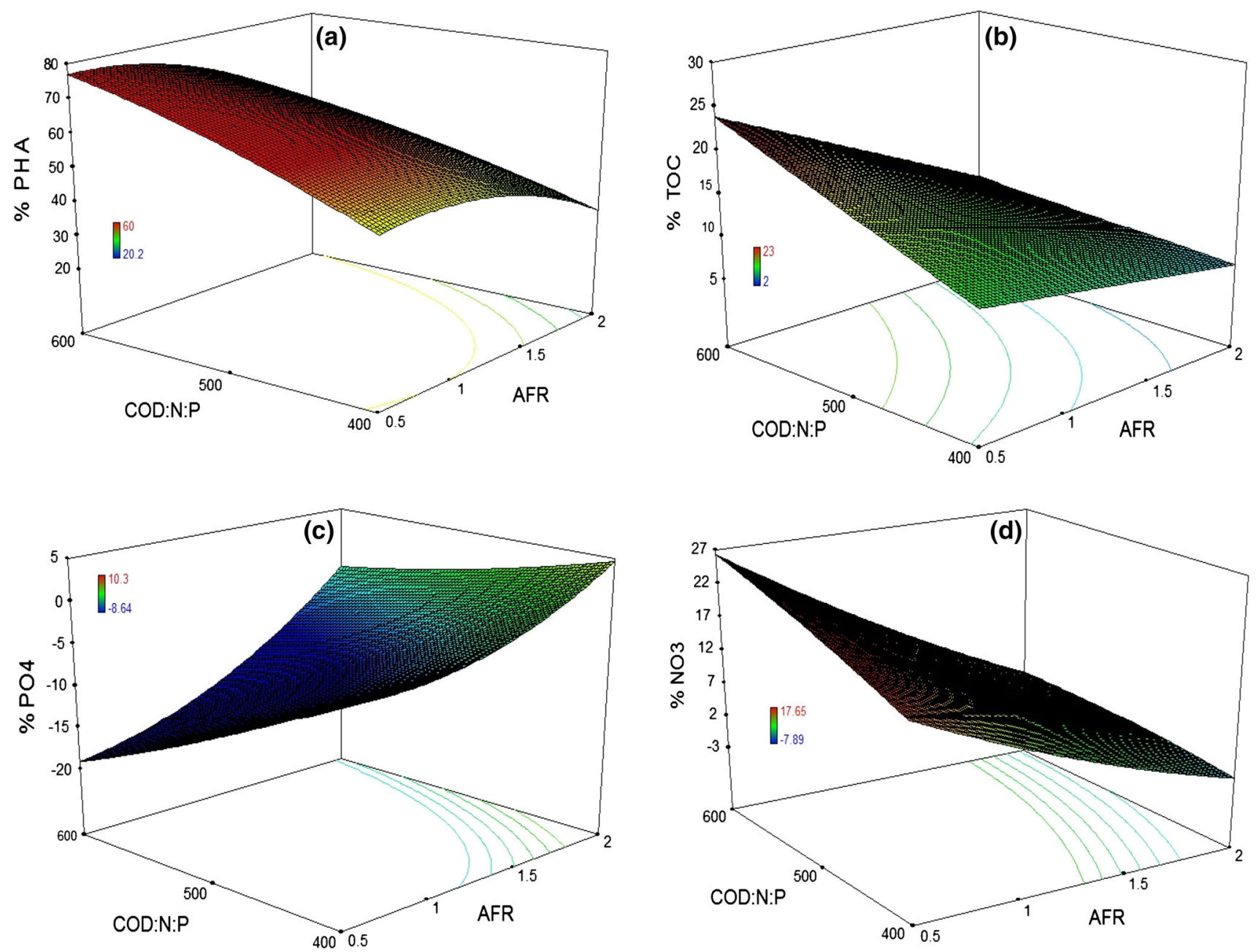

Fig. 3 Response surface plot showing variation in predicted PHA production, organic and nutrient removal of POME as a function of COD:N:P and AFR for incubation $9 \mathrm{~h}$ (CL and SFR were fixed at $18 \mathrm{~h}$ and $20 \mathrm{~mL} / \mathrm{min}$, respectively)

2.04 (in regression analysis) for PHA production (taken as one example) implies that the model is statistically significant (degree of freedom, DF $>F$ ). The value of $p<0.05$ indicates that the model terms are also significant. However, $p$ value must be higher than $F$ value, and in our study it was not observed. Therefore, the coefficient of determination $\left(R^{2}\right)$ was calculated to be 0.769 , indicating that the model could only achieve $76.9 \%$ of the variability. The "lack of fit tests" compares the residual error to the "Pure Error" from replicated design points. The "lack of fit $F$ value" of 10.87 (for \%PHA) implies the lack of fit is significant $(F>\alpha)$, since $\alpha$ was initially set at 2 . However, with inconsistent variability of $F$ and $p$ value, implies that the predictive model is not statistically correct and that the process appears insignificant to the model. There is only $0.08 \%$ chance that a "lack of fit $F$ value" this large could occur due to the noise factor. The analysis from response surface analysis was initially carried out using full quadratic terms (i.e., linear, interaction, and squares). Based on the $p$ value $(<0.2)$ for PHA production, the results indicate that only linear terms are significant, while the square terms considered insignificant. The $R^{2}$ value of the model is acceptable (79.6\%) but the $p$ value of the lack of fit test (0.008) indicates its significance. As a result, the estimated models fit the experimental data is only valid in small-scale reactions.

Three-dimensional response surfaces were plotted on the basis of the model equation, to investigate the interaction among the variables and to determine the optimum concentration of each factor for maximum PHA production (incorporated with percentage of TOC, $\mathrm{PO}_{4}$, and $\mathrm{NO}_{3}$ removal) by mixed cultures. The effects of varying the COD:N:P and other variables are shown in Fig. 2, which demonstrates that the response surfaces for the three 
combinations were similar to \% PHA production, \% TOC, and $\% \mathrm{NO}_{3}$ removals. However, $\% \mathrm{PO}_{4}$ removal was monitored irreversible than those three responses. The increment of AFR (1.5-2.0 L/min) and COD:N:P (400-600 g $\mathrm{COD} / \mathrm{g} \mathrm{N}$ and $200 \mathrm{~g} \mathrm{COD} / \mathrm{g} \mathrm{P}$ ) reflected to the $\mathrm{PO}_{4}$ removal decrement from 0 to $15 \%$.

The interactive effect of carbon, nitrogen and phosphorus concentrations on PHA production was clearly observed in Fig. 3. At the lowest ratio of COD:N:P (450 g $\mathrm{COD} / \mathrm{g} \mathrm{N}$ and $100 \mathrm{~g} \mathrm{COD} / \mathrm{g} \mathrm{P}$ ), the increment in oxygen supply had little effect on PHA production, TOC, $\mathrm{NO}_{3}$, and $\mathrm{PO}_{4}$ removal for above $1 \mathrm{~L} / \mathrm{min}$. Meanwhile, if the ratio more than $550 \mathrm{~g} \mathrm{COD} / \mathrm{g} \mathrm{N}$ (oxygen supply is $<1 \mathrm{~L} / \mathrm{min}$ ), most of the PHA production and nutrient reduction (TOC and $\mathrm{NO}_{3}$ ) efficiencies reached high value. The ANOVA suggested that no statistically significant effect of HRT and SFR on the PHA production. The principal factor that influenced PHA accumulation was the concentration of oxygen in the gas phase. The PHA concentration increased with decreasing amounts of oxygen. The results clearly suggest that oxygen limitation has an important role in PHA production and the dissolved oxygen in the cultivation broth should be controlled for attaining a high productivity of PHA.

\section{Optimization analysis}

The numerical optimization seeks a point that maximizes this desirability function. Tables 4,5 showed constraints for the responses and factors, and optimal points based on the desirability function. The propagation of error (POE) method makes the production process robust (insensitive) to variations in input factors. Point prediction was used to make predictions for responses at any factor combination (COD:N:P, AFR, CL, and SFR). As shown in Table 4, the desirability value indicated that the starting point (predicted point), which was assumed and accepted earlier. The overall desirability is a measure of how well the variable is satisfied for the combined goals (in all of the responses). Overall desirability (D) has a range $0-1$ whereas one may represents the ideal case of zero that indicates one or more responses are outside their acceptable limits. The study found that the lowest D is 0.87 for \%TOC removal, while the highest value appeared at 0.948 for $\% \mathrm{NO}_{3}$ removal. Therefore, the composite desirability reached to 0.921 , and the global solution (factor combination) was acceptable for numerical optimization with POE.

In order to analyze the main interaction effect, the graphic analysis of this optimization is shown in Fig. 4. This optimization plot allows user to interactively change the input variable settings to perform sensitivity analyses and possibly improve the initial solution (e.g. COD:N:P, AFR, etc.). The local desirability (d) in this study was 
Table 5 Numerical optimization with the overall predicted and desirability obtained from response optimizer with the POME

\begin{tabular}{|c|c|c|c|c|c|}
\hline Responses & Predicted & Desirability & Starting point & Global solution & $\begin{array}{l}\text { Composite } \\
\text { desirability }\end{array}$ \\
\hline $\begin{array}{l}\% \mathrm{PHA} \\
\text { production }\end{array}$ & 66.29 & 0.927 & $\begin{array}{l}\text { CODNP ratio }=600 \mathrm{~g} \mathrm{COD} / \mathrm{g} \mathrm{N} \text { and } \\
200 \mathrm{~g} \mathrm{COD} / \mathrm{g} \mathrm{P}\end{array}$ & $\begin{array}{l}\text { CODNP ratio }=509 \text { g COD } / \mathrm{g} \mathrm{N} \text { and } \\
200 \mathrm{~g} \mathrm{COD} / \mathrm{g} \mathrm{P}\end{array}$ & 0.921 \\
\hline $\begin{array}{l}\text { \% TOC } \\
\text { removal }\end{array}$ & 19.39 & 0.870 & $\mathrm{DO}=0.51 / \mathrm{min}$ & $\mathrm{DO}=0.59 \mathrm{l} / \mathrm{min}$ & \\
\hline $\begin{array}{l}\% \mathrm{PO}_{4} \\
\text { removal }\end{array}$ & -9.24 & 0.942 & $\mathrm{HRT}=18 \mathrm{~h}$ & $\mathrm{HRT}=20 \mathrm{~h}$ & \\
\hline $\begin{array}{l}\% \mathrm{NO}_{3} \\
\text { removal }\end{array}$ & 2.80 & 0.948 & $\mathrm{FR}=20 \mathrm{ml} / \mathrm{min}$ & $\mathrm{FR}=20 \mathrm{ml} / \mathrm{min}$ & \\
\hline
\end{tabular}

Fig. 4 Response optimizer for best factor-response analysis for PHA production and nutrient removal $(C O D$ chemical oxygen demand, $A F R$ air flow rate, $C L$ cycle length, $S F R$ substrate feeding rate, TOC total organic carbon)

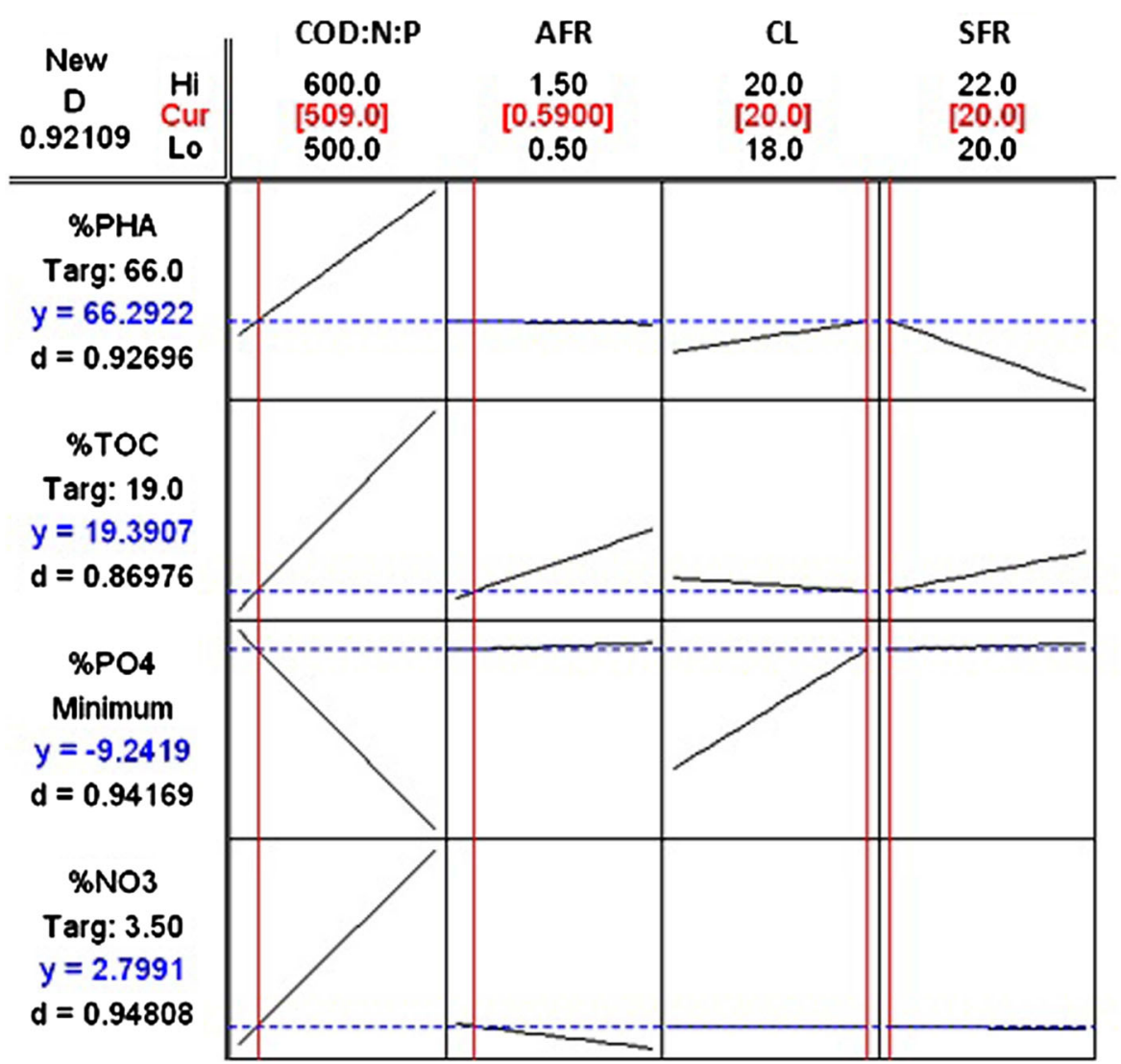

obtained at range $0.86-0.95$, which indicated the prediction values of $\mathrm{PHA}, \mathrm{TOC}, \mathrm{NO}_{3}$, and $\mathrm{PO}_{4}$ was acceptable. Therefore, the curve line has a sharp shape compared to other influence factors. As a conclusion, carbon ratio must be well controlled in order to reach both PHA production and nutrient removal (Kulpreecha et al. 2009). At the same time, the study also suggests that the AFR, CL and SFR should be operated at $0.59 \mathrm{~L} / \mathrm{min}, 20 \mathrm{~h}$, and $22 \mathrm{~mL} / \mathrm{min}$, respectively.

The results from Pareto chart (Fig. 5) suggested that attaining a high production of PHA required a limited of the DO and high COD:N:P. A second set of experiment was carried out under selected range of AFR (0.5-1.5
L/min). The concentrations of carbon, nitrogen, and phosphate sources were varied in a narrow interval around the central composite optimum in a 16 factorial experimental design. The \%PHA production was sharply reduced at limiting COD:N:P and/or AFR in comparison with the two-level factorial optimal process. When harvesting a high PHA production during feast period, COD:N:P and AFR gave significant effect to TOC and $\mathrm{NO}_{3}$ removal. Therefore, $\mathrm{NO}_{3}$ concentration could be influential for PHA production rather than the degradation of organic constituents only. The present study showed no increase in COD:N:P in the new experimental range of variables and the optimal conditions for maximum production (\% $\% H A$ ), 
Pareto Chart of the Effect

(response is \% PHA), Alpha=.10)
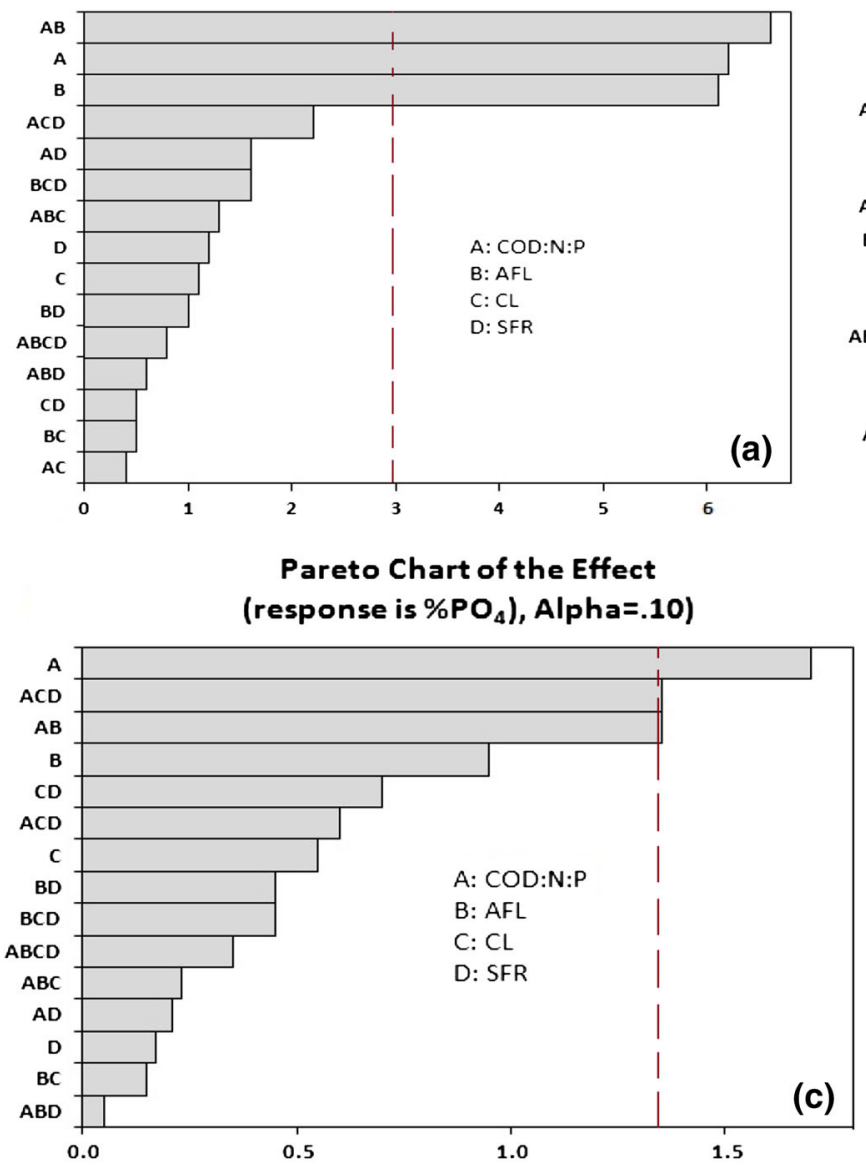

Pareto Chart of the Effect

(response is \%TOC), Alpha=.10)

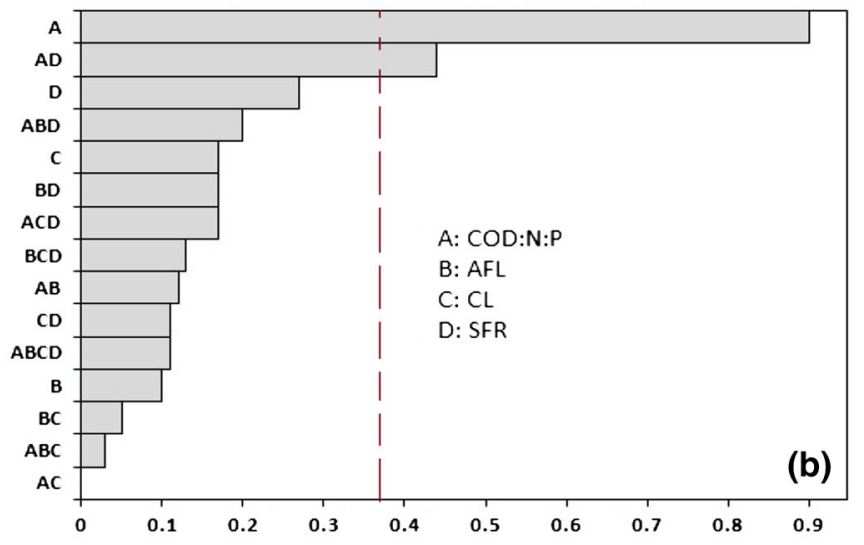

Pareto Chart of the Effect (response is \% $\mathrm{NO}_{3}$ ), Alpha=.10)

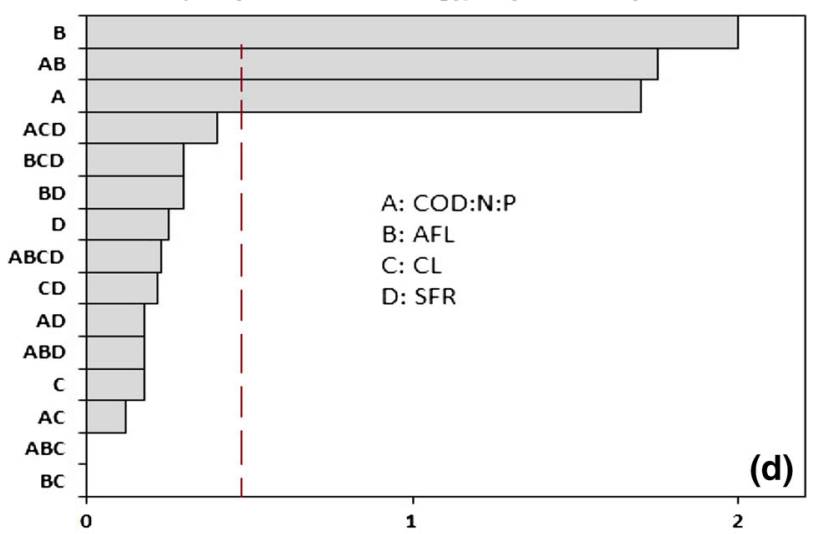

Fig. 5 Pareto chart for PHA production, total organic carbon, and nutrient removal at different variables $(\alpha 0.1, C O D$ chemical oxygen demand, $A F L$ air flow rate, $C L$ cycle length, SFR substrate feeding rate). Line of significance is depicted as dotted line and determined by MINITAB ${ }^{\mathrm{TM}}$

and nutrient removal $\left(\% \mathrm{TOC}, \% \mathrm{PO}_{4}\right.$, and $\left.\% \mathrm{NO}_{3}\right)$ in the two-level factorial design. Thus, a culture medium for maximizing PHA production should be in the range 450-500 g COD/g N, 180-200 as $\mathrm{g}$ COD/g P, and $\mathrm{AFR}=0.5-0.6 \mathrm{~L} / \mathrm{min}(5-6.2 \%$ of DO saturation). A high transfer rate of oxygen should be maintained in the bioreactor during feast period for better storage capacity. Model verification results showed that the control of COD:N:P and AFR of the medium had a strong effect on PHA production, TOC, and $\mathrm{NO}_{3}-\mathrm{N}$ removal. No significant effect has been observed for SFR and CL. However, the increment of $\mathrm{PO}_{4}-\mathrm{P}$ concentration will be occurred during high PHA production. After 7 days of culture, the biomass concentrations obtained were $10 \%$ higher than single factor in the optimized conditions. The biomass concentrations were successfully enhancing the PHA content in their cells (increase up to $60 \%$ of total dry weight) after reconfiguring the operational condition. The increased PHA production was obtained at COD: $\mathrm{N}=509 \mathrm{~g}$ COD $/ \mathrm{g} \mathrm{N}$,
COD: $\mathrm{P}=200 \mathrm{~g}$ COD $/ \mathrm{g} \mathrm{P}, \mathrm{AFR}=0.59 \mathrm{~L} / \mathrm{min}, \mathrm{FR}=$ $20 \mathrm{~mL} / \mathrm{min}$, and $\mathrm{CL}=20 \mathrm{~h}$. Thus, the overall bioprocess optimization approach using the statistical method is inefficient and time consuming.

\section{Conclusion}

Palm oil mill effluent was found to be the best substrate for PHA production. The results showed initial limiting condition of $\mathrm{N}$ and $\mathrm{P}$ of the culture medium significantly affects biomass and PHA productivities. The increment of AFR affected a low PHA production, TOC removal, and $\mathrm{NO}_{3}$ removal. The $\mathrm{PO}_{4}$ resulted in adverse effect, but the values still in non-removal efficiency. The control of COD:N:P and AFR of the medium had a strong effect on PHA production, TOC, and $\mathrm{NO}_{3}-\mathrm{N}$ removal. No significant effect has been observed for SFR and CL. However, the increment of $\mathrm{PO}_{4}-\mathrm{P}$ concentration will be occurred 
during the high PHA production. Through a statistically designed optimization, the PHB production, TOC and $\mathrm{NO}_{3}-\mathrm{N}$ removal could be increased from an average of 66 , 19 , and $3 \%$, respectively. From this optimization, the non$\mathrm{PO}_{4}$ removal could be minimized as low as $-9 \%$ during feast period.

Acknowledgments The authors are pleased to acknowledge the Ministry of Science and Innovation (MOSTI) for providing the research grant (IRPA, vot 74262) and National Foundation for Tropical Country (WOTRO) of the Netherlands for financial support. We are also grateful to Universiti Teknologi Malaysia (UTM) and Technical University of Delft for their facilities and training opportunities.

\section{References}

Ahn WS, Park SJ, Lee SY (2000) Production of poly(3-hydroxybutyrate) by fed-batch culture of recombinant Escherichia Coli with a highly concentrated whey solution. Appl Environ Microbiol 66:3624-3627

Anderson AJ, Haywood GW, Williams DR, Dawes EA (1990) The production of polyhydroxyalkanoates from unrelated carbon sources. In: Dawes EA (ed) Novel biodegradable microbial polymers. Kluwer Academic Publishers, Netherlands, pp 119-129

Bocchini DA, Alves-Prado HF, Baida LC, Roberto IC, Gomes E, Da Silva R (2002) Optimization of xylanase production by Bacillus circulans D1 in submerged fermentation using response surface methodology. Process Biochem 38:727-731

Clesceri LS, Eaton AD, Greenberg AE, Franson MAH, APHA, AWWA, WEF (1995) Standard methods of the examination of water and wastewater, 19th edn. American Public Health Association, Washington

Dey G, Mitra A, Banerjee R, Maiti BR (2001) Enhanced production of amylase by optimization of nutritional constituents using response surface methodology. Biochem Eng J 7:227-231

Fuchtenbusch B, Wullbrandt D, Steinbuchel A (2000) Production of polyhydroxyalkanoic acids by Ralstonia eutropha and Pseudomonas oleovorans from oil remaining from biotechnological rhamnose production. Appl Microbiol Biotechnol 53:167-172

Hassan MA, Nawata O, Shirai Y, Nor Aini AR, Yee PL, Arif A, Abdul Karim MI (2002) A proposal for zero emission from palm oil industry incorporating the production of polyhydroxyalkanoates from palm oil mill effluent. J Chem Eng 35:9-14

Hong K, Leung YC, Kwok SY, Law KH, Lo WH, Chua H, Yu PHF (2000) Construction of recombinant Escherichia coli strains for polyhydroxybutyrate production using soy waste as nutrient. Appl Biochem Biotechnol 84-86:381-390

Kulpreecha S, Boonruangthavorn A, Meksiriporn B, Thongchul N (2009) Inexpensive fed-batch cultivation for high poly(3hydroxybutyrate) production by a new isolate of Bacillus megaterium. J Biosci Bioeng 107:240-245

Kumar S, Katiyar N, Ingle P, Negi S (2011) Use of evolutionary operation (EVOP) factorial design technique to develop a bioprocess using grease waste as a substrate for lipase production. Bioresour Technol 102:4909-4912
Lam MK, Lee KT (2011) Renewable and sustainable bioenergies production from palm oil mill effluent (POME): win-win strategies toward better environmental protection. Biotechnol Adv 29:124-141

Lee SL, Chen WC (1997) Optimization of medium composition for the production of glucosyltransferase by Aspergillus niger with response surface methodology. Enzyme Microb Technolnol 21:436-440

Malaysia Palm Oil Board (2005) Palm oil update-for the latest information on palm oil. 25(09/05). Ministry of Plantation Industries and Commodities, Malaysia

Marchessaul RH (2009) Polyhydroxyalkanoate (PHA) history at Syracuse University and beyond. Cellulose 16:357-359

Md Din MF, Yunus S, Ujang Z, Salim MR, Loosdrecht MCM, Ahmad A, Marpongahtun M (2005) A complete analysis on PHA production and their rates using sunflower oil and mixed cultures: hydraulic retention times (HRT) effects. J Sains Kimia 9: $31-41$

Montgomery DC, Peck EA (1982) Introduction to Linear regression analysis. John Wiley \& Sons, New york

Mumtaz T, Yahaya NA, Aziz SA, Rahman NAA, Yee PL, Shirai Y, Hassan MA (2010) Turning waste to wealth-biodegradable plastics polyhydroxyalkanoates from palm oil mill effluent-a Malaysian perspective. J Cleaner Product 18:1393-1402

Myers RH, Montgomery DC (2002) Response surface methodology: process and product optimization using designed experiments, 2nd edn. John Wiley and Sons, New York

Otari SV, Ghosh JS (2009) Production and Characterization of the polymer polyhydroxy butyrate-copolyhydroxy valerate by Bacillus Megaterium NCIM 2475. Curr Res J Biol Sci 1:2326

Reddy CSK, Ghai R, Rashmi T, Kalia VC (2003) Polyhydroxyalkanoates: an overview. Bioresour Technol 87: 137-146

Rodríguez-Carmona E, Bastida J, Manresa A (2011) Utilization of agro-industrial residues for poly(3-hydroxyalkanoate) production by Pseudomonas aeruginosa 42A2 (NCIMB 40045): optimization of culture medium. J Am Oil Chem Soc $89: 111-122$

Salehizadeh H, Van Loosdrecht MCM (2004) Production of polyhydroxyalkanoates by mixed culture: recent trends and biotechnical importance. Biotechnol Adv 22:261-279

Salmiati Z, Ujang MR, Salim MF, Md Din MF, Ahmad MA (2007) Intracellular biopolymer productions using mixed microbial cultures from fermented POME. Water Sci Technol 56: 179-185

Serafim LS, Lemos PC, Oliveira R, Reis MAM (2004) The optimization of polyhydroxybutyrate production by mixed cultures submitted to aerobic dynamic feeding conditions. Biotechnol Bioeng 87:145-160

Sreekumar O, Chand N, Basappa AC (1999) Optimization and interaction of media components in ethanol production using Zymomonas mobilis by response surface methodology. J Biosci Bioeng 83:334-338

Tokiwa Y, Calabia BP (2004) Degradation of microbial polyesters. Biotechnol Lett 26:1181-1189

Vijayendra SVN, Rastogi NK, Shamala TR, Anil Kumar PK, Kshama L, Joshi GJ (2007) Optimization of polyhydroxybutyrate production by Bacillus sp. CFR 256 with corn steep liquor as a nitrogen source. Indian J Microbiol 47:170-175

Watier D, Dubourguier HC, Leguerinel I, Hornez JP (1996) Response surface models to describe the effects of temperature, ph, and ethanol concentration on growth kinetics and end products of a Pectinatus sp. Appl Environ Microbiol 62:1233-1237 
Wong AL, Chua H, Lo WH, Yu PHF (2000) Synthesis of bioplastics from food industry wastes with activated sludge biomass. Water Sci Technol 41:55-59
Yu PH, Chua H, Huang AL, Lo W, Chen GQ (1998) Conversion of food industrial wastes into bioplastics. Appl Biochem Biotechnol 70:603-614 